\title{
Placental Changes in Gestational Diabetes Controlled with Insulin versus Diet without Insulin Compared with Normal Uncomplicated Pregnancy: Clinical and Histopathological Study
}

\author{
Abeer M. Hafez ${ }^{1}$, Yasser S. Sheta ${ }^{2}$, Elsayed A. Elgohary ${ }^{3}$, Salah F. Alsayed ${ }^{4}$ \\ ${ }^{1}$ Departments of Pathology, Faculty of Medicine, Zagazig University \\ ${ }^{2,3,4}$ Internal Medicine, Faculty of Medicine, Zagazig University
}

\begin{abstract}
The fetus, placenta and mother constitute a triad of contributors to pregnancy outcome. Whenpregnancy is complicated by a medical problem like, diabetes mellitus which affects maternal health, architecture and functions of the placenta may even jeopardize the fetal normalcy. The placenta being thebridge between maternal and fetal activities, considered as a window through which maternal dysfunctionsand their impacts on fetal well being can be understood.The aim of this research isstudying the pathological changes of placentae of women with gestational diabetes mellitus and tocompare the results with normal pregnancies. Methods: It was an observational study conducted in Zagazig University hospitals, 20 placentaefrom pregnant women clinically diagnosed with gestational diabetes mellitus (GDM) controlled only with diet and life style modificationsand another 20 placentaefrom pregnant women clinically diagnosed with gestational diabetes mellitus (GDM) controlled with insulin and 20 placentae fromuncomplicated normal pregnant womenwere collected from labour room and operation theatre of departmentof obstetrics and gynaecology. Confirmedgestational diabetic caseswere selected purposively from gestational diabetes clinic of endocrinology unit while controls were taken sequentially. Pathologic features of each placentawere recorded in histopathology department. Results:The results showed that placental weight, diameter, surface area and central thickness from diabetic mothers controlled with insulin were significantly more than diabetic mothers controlled only by diet or mothers of normal uncomplicatedpregnancies, while no significant differences were observed in shape and site of umbilical cord insertion. The terminal villi in placentae of GDM controlled by insulin showed a significant varying degreeof changes like, the increased number of syncytial knots, villous edema and fibrinoid necrosis however, these changes were very minimal in cases of GDM treated only with diet and controlled without need of insulin. Conclusion:The placentae ofwomenwith gestational diabetesmellitus treated with insulin even controlled showsignificant variation in gross morphology and light microscopy thatcan be associated with impaired function ofplacenta, leading to possible adverse perinataloutcome. In the other hand, the placentae ofwomenwith gestational diabetesmellitus controlled with diet alone showed minimal changes with no significant differences from normal uncomplicated pregnancy. Control of GDM or better prevention by education, diet, optimum weight control and life style modifications should be strictly encouraged and insulin use should be the last resort.
\end{abstract}

Keywords: gestational diabetes, pregnancy, insulin, placenta, diet

\section{Introduction}

Since it is one the commonest metabolic problemsof pregnancy, an accurate diagnosis of gestationaldiabetes mellitus (GDM), i.e., high plasma glucose firstidentified during pregnancy, is critical to the care ofpregnant women[1]. Five decades ago, GDM was usedto detect pregnant women who were at a higher riskof developing type 2 diabetes mellitus (DM2) afterchildbirth[1, 2]. Currently, GDM is used to predict morbidityin index pregnancy; many trials have confirmed that itis related to multiple maternal and fetal complicationslike pre-eclampsia, caesarean sections and birth injuries[2]. Pregnancy is a diabetogenic state by virtue of various physiological changes which causeinsulin resistance. In normal pregnancy, glucose tolerance decreases by third trimester, though plasma levels of insulin increases [3].About 2\%to5\% of the total pregnanciesmay be affected by diabetes mellitus. Amongpregnancies complicated by diabetes mellitus,about $65 \%$ cases involve gestational diabetes mellituswhereas $35 \%$ cases are associated with pre-existing diabetes mellitus [4.]. Placenta is a vital organ for fetal developmentand is a mirror of maternal and fetal status. Itderived from both fetal and maternal tissues, the maternal portion being the decidua basalisand the fetal portion is chorionfrondosum [5].So, as amirror,placenta reflects the intra-uterinestatus of the fetus. Its metabolic functions arecomplex and it undergoes changes continuouslythroughout gestation inweight, structure, shapeand function in order to support prenatal life [6].InGDM, when the intra-uterine environment forfetus become hostile, the placenta tries to exertits reserve capacity by changing itsmorphological structure, as well as somepathological changes occur that arecompounded principally of some disturbancesin its normal rate of maturation [7].Some workers have claimed that placentas fromdiabetic women show no unusual feature while others haveobserved frequent abnormalities in such placentas but failedto agree on any consistent pathologic pattern.This confusion is partly due tothe inclusion, in many studies, of gestational diabetesmellitus (GDM) in whom there was either superadded pre-eclamptictoxemia or intrauterine fetal death; as thesecomplications may obscure the significance of diabetic placentas. Also the degree of control and the modality used in control either with insulin or diet alone should be taken in consideration. So it is therefore not surprising that the result obtainedhave been inconsistent and indeed, often contradictory [8]. In our study, all the patients with GDM were perfectly controlled whatever the modality

\section{Volume 4 Issue 12, December 2015}




\section{International Journal of Science and Research (IJSR) \\ ISSN (Online): 2319-7064}

Index Copernicus Value (2013): 6.14 | Impact Factor (2014): 5.611

of treatment with insulin or without. Also other co-morbid condition such as hypertension, hypothyroidism, anaemia,jaundice, and maternal malnutrition even tobacco abuse, smoking, alcoholism etc. were excluded from study to create a chance of studying the true effect of GDM and modality of treatment on placenta without bias of other pathologic co-morbid conditions or even diabetes control status which, ofcourse well known active player.

\section{Materials and Methods}

It was a prospective comparative study,conducted in Zagazig University hospitals between September 2013 and September 2014. After due approval from institutional ethics committeeandinformed consent was obtained,20 placentaefrom pregnant women clinically diagnosed with gestational diabetes mellitus (GDM) controlled only with diet and life style modifications and another 20 placentaefrom pregnant women clinically diagnosed with gestational diabetes mellitus (GDM) controlled with insulin and 20 placentae fromuncomplicated normal pregnant womenwere collected from labour room and operation theatre of departmentof obstetrics and gynaecology. Confirmedgestational diabetic caseswere selected purposively from gestational diabetes clinic of endocrinology unit while controls were taken sequentially. Pathologic features of each placentawere recorded in histopathology department.A pre-structured and pre-tested proforma wasused to collect the data. Personal details ofmothers like name, age and address wererecorded. Social history regarding habits ofmothers like smoking, tobacco chewing andconsumption of alcohol were taken. Detailedobstetric history regarding parity, period ofgestation, bad obstetric history in past, type ofpregnancy (singleton or multiple), mode ofdelivery and abruptio placentae was recorded.Medical history regarding anaemia, jaundice,malnutrition, cardiovascular disease, cerebrovasculardisease, respiratory disorders,psychiatric illness and any other major illnesswas taken and recorded. A general physicalexamination was done for anaemia, jaundiceand nutritional status of mothers. Bloodpressure, weight and relevant investigationswere recorded from bed head tickets.The placentae with attached membranes andumbilical cordwere collected soon after deliveryand washed in running tap water to clean allblood. Surface driedbetweenblotting papers andexamined for morphological characteristics likeshape and type of insertion of umbilical cord. The membranes weretrimmed and the cord was cut at about 2 centimeters fromits insertion. The placentawasthenweighed usingbabyweighingmachine. Thecentral thickness wasmeasured by long knittingneedle. Two diameters of the placenta weremeasured with the non stretchable measuringtape and the mean of the two was calculated.Theevaluation ofmacroscopic placentalparameterswas performed according to protocols publishedby Benirsckhe [9].

For light microscopy, two $\mathrm{cm}$. wedge of tissue wastaken from the centre of each placenta and fixed in $10 \%$ formalin for one week. The tissue was dehydrated andfollowed by embedding in paraffin and 7 micron serialsections were generated with the help of rotatory microtome.The tissue sections were stained with hematoxylene andeosin.
Histological appearance of the terminal villi ofplacentas was assessed and following observations weremade.Trophoblast:The number and position ofsyncytiotrophoblast, syncytial knots and cytotrophoblastnuclei was assessed.Villousstroma:The density of villous stroma was assessedqualitatively by looking for the presence of collagen fibresand density of the background fibrillar material.Fetal capillary:Evidence of capillary proliferation andobstruction within the capillary lumen was sought in eachcase $[10,11]$.

Inclusion criteria: Pregnant women with agebetween 20-38 years, para 1 to 5, gestationalage between 37-42 weeks, deliveries by either vaginal route or caesarean section with singleton pregnancy were included. The control group comprised pregnant women who did not experience complications during pregnancy and who had normal laboratory tests while study group comprised pregnant women with clinically confirmed gestational diabetes mellitus. Exclusion criteria:Pregnant women who did experience any complication during pregnancy like hypertension, hypothyroidism, anaemia, abruptio placentae, multiple pregnancies, jaundice, maternal malnutrition, cardiovascular disease, cerebro-vascular disease, psychiatric illness, respiratory disorders, tobacco abuse, smoking, alcoholism etc. were excluded from study.

Statistical analysis:The data was entered on Microsoft excel 2010 and analyzed. The results for each parameter (numbers and percentages) for discrete data and average (mean \pm standard deviation) for continuous data are presented in Tables. Proportions were compared using Chi-square test of significance. The F test was used to determine whether there was a statistical significant differencebetween control and studied groups. A $P$-value of less than 0.05 was considered to be statistically significant.

\section{Results}

In present study, the meanage \pm SD (years), weight \pm SD $(\mathrm{kg})$, height $\pm \mathrm{SD}(\mathrm{cm})$ andthe body mass index $(\mathrm{BMI}) \pm$ $\mathrm{SD}(\mathrm{Kg} / \mathrm{m} 2)$ were studied in all groups of study and summarized in table 1. Generally speaking; age, weight and BMI ware more in GDM group controlled with insulin than the other two groups but we cannot consider this note of clinical significance due to limited number of the patients and purposeful mode of patients choice.

Table 1: Distribution of characteristics of study subjects

\begin{tabular}{|c|c|c|c|}
\hline Characteristic & $\begin{array}{c}\text { GDM } \\
\text { controlled } \\
\text { with insulin } \\
(\text { Mean } \pm \text { SD) } \\
n=20\end{array}$ & $\begin{array}{c}\text { GDM controlled } \\
\text { with diet without } \\
\text { insulin } \\
\text { (Mean } \pm \text { SD) } \\
n=20\end{array}$ & $\begin{array}{c}\text { Control } \\
\text { (Mean } \pm \text { SD) } \\
n=20\end{array}$ \\
\hline Age $($ years) & $30.4 \pm 3.5$ & $29.3 \pm 4.3$ & $29.3 \pm 4.3$ \\
\hline Weight $(\mathrm{kg})$ & $79.7 \pm 8.2$ & $66.2 \pm 6.1$ & $66.2 \pm 6.1$ \\
\hline Height $(\mathrm{m})$ & $1.57 \pm 0.1$ & $1.56 \pm 0.1$ & $1.56 \pm 0.1$ \\
\hline BMI $(\mathrm{Kg} / \mathrm{m} 2)$ & $32.3 \pm 1.5$ & $27.09 \pm 1.8$ & $27.09 \pm 1.8$ \\
\hline
\end{tabular}

In controls majority of cases were in para-2 (40\%) followed by para-1 (35\%), and in GDM group controlled with insulin majority of cases were in para-1 (45\%)followed by para- 2 


\section{International Journal of Science and Research (IJSR) \\ ISSN (Online): 2319-7064 \\ Index Copernicus Value (2013): 6.14 | Impact Factor (2014): 5.611}

(35\%) while in GDM group controlled with diet without insulin cases with the same like the control group.

The mean placental weight \pm SD (gram), the mean placental diameter $\pm \mathrm{SD}(\mathrm{cm})$, the mean placental central thickness \pm $\mathrm{SD}(\mathrm{cm})$ and the mean placental surface area $\pm \mathrm{SD}(\mathrm{cm} 2)$ were calculated in all groups of study and summarized in table 2.There were highly significant differences in these parameters in GDM group controlled with insulin in comparison with the other two groups $(\mathrm{p}<0.01)$ while no significant differences of these parameters in GDM group controlled with diet without insulin in comparison of control group $(\mathrm{p}>0.05)$.

Table 2: Placental morphometry between gestational diabetics and normal pregnancies

\begin{tabular}{|c|c|c|c|}
\hline $\begin{array}{c}\text { Parameters } \\
\text { Of placenta }\end{array}$ & $\begin{array}{c}\text { GDM } \\
\text { controlled } \\
\text { with insulin } \\
(\text { Mean } \pm S D) \\
n=20\end{array}$ & $\begin{array}{c}\text { GDM controlled } \\
\text { with diet without } \\
\text { insulin } \\
(\text { Mean } \pm S D) \\
n=20\end{array}$ & $\begin{array}{c}\text { Control } \\
(\text { Mean } \pm S D) \\
n=20\end{array}$ \\
\hline weight $(\mathrm{gram})$ & $437.3 \pm 52.1$ & $392.8 \pm 44.6$ & $389.4 \pm 31.3$ \\
\hline diameter $(\mathrm{cm})$ & $17.1 \pm 1.1$ & $15.6 \pm 1.8$ & $15.2 \pm 1.3$ \\
\hline thickness $(\mathrm{cm})$ & $2.3 \pm 0.8$ & $2 \pm 0.8$ & $1.9 \pm 0.4$ \\
\hline surface $(\mathrm{cm} 2)$ & $218.3 \pm 36.9$ & $188.9 \pm 34.2$ & $181.6 \pm 32.7$ \\
\hline
\end{tabular}

In control group $40 \%$ placentae were of round shaped and $60 \%$ were of oval shaped, and in GDM group controlled with insulin 35\% of placentae were round shaped and $65 \%$ were oval shaped while in GDM group controlled with diet without insulin were same like control group. The difference was not significant $(\mathrm{p}>0.05)$.

In control group umbilical cord insertion was central in $25 \%$, eccentric in $60 \%$ and marginal in $15 \%$ of placentae and in GDM group controlled with insulin it was central in $20 \%$, eccentric in $65 \%$ and marginal in $15 \%$ of placentae while inGDM group controlled with diet without insulin was central in $20 \%$, eccentric in $60 \%$ and marginal in $20 \%$ of placentae. And again the difference was not significant ( $p>$ $0.05)$.

The light microscopic findings.

The terminal villi in placentae of GDM group controlled with insulin showed a varying degreeof changes like, the increased number of syncytial knots(Fig.1). The stroma of the villi demonstrated villous edema(Fig. 2) and fibrinoid necrosis (Fig. 3). Villous fibrosis (Fig. 4) and foetalcapillary proliferation (Fig. 5) was observed in very limited number. The histopathological changes in GDM group controlled with diet without insulin ware minimal changes in the terminal villi and none of them showed villous edema,villous fibrosis or fetal capillary proliferation resemble normal placntae.

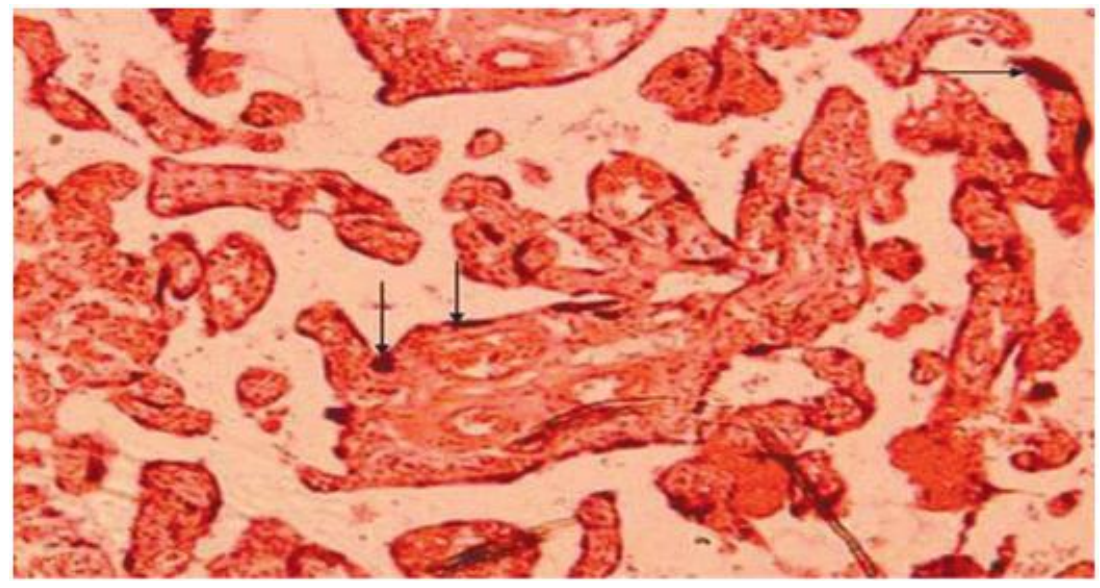

Arrow marked areas of syncytial knot formation. (H \& E40X).

Figure 1

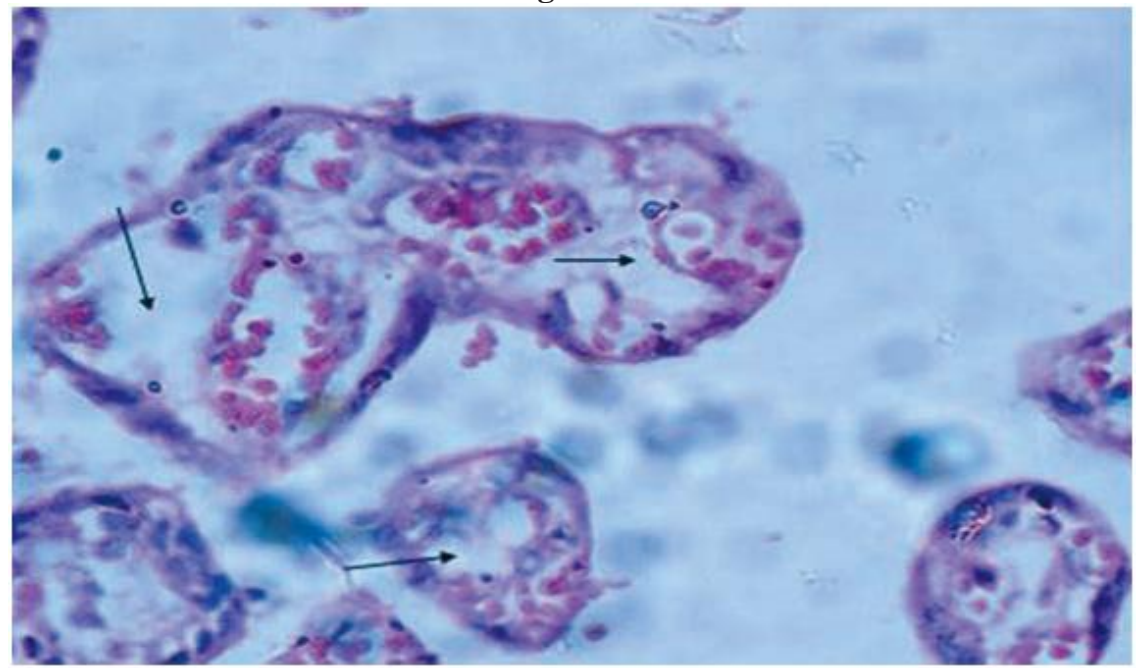

Arrow marked areas of villous edema. (H \& E 40X).

Figure 2

Volume 4 Issue 12, December 2015 


\section{International Journal of Science and Research (IJSR) \\ ISSN (Online): 2319-7064}

Index Copernicus Value (2013): 6.14 | Impact Factor (2014): 5.611

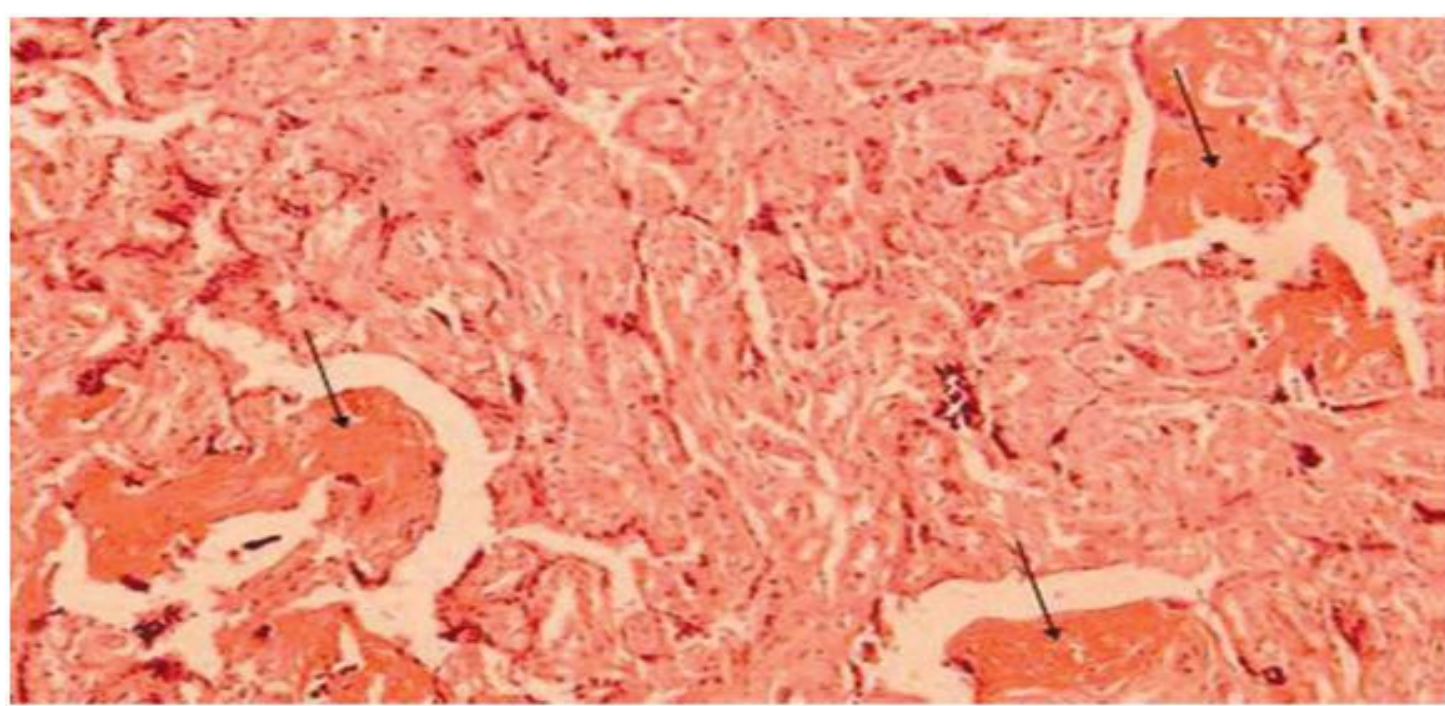

Arrow marked areas of fibrinoid necrosis and congestion ofvilli. (H \& E 40X).

Figure 3

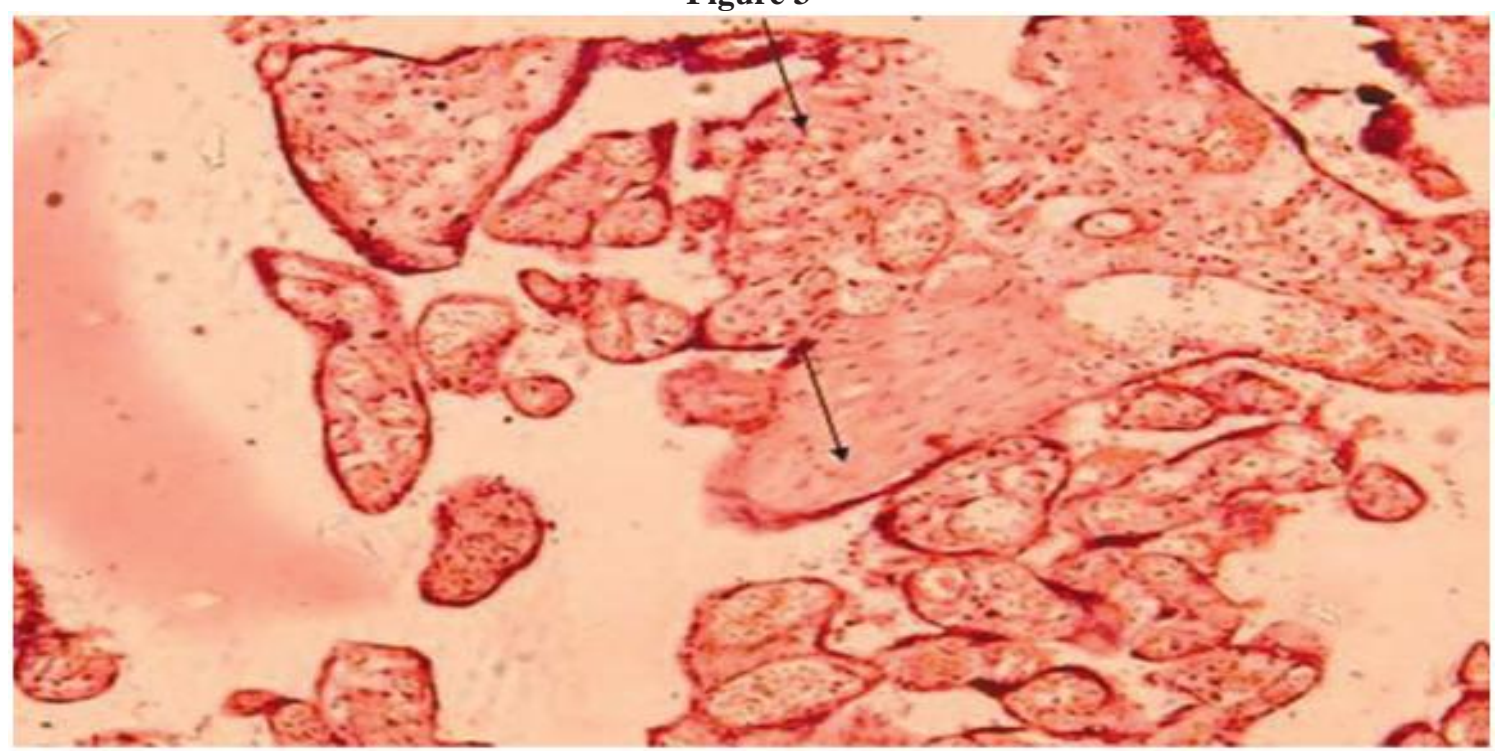

Arrow marked areas of villous fibrosis. (H \& E 40X)

Figure 4

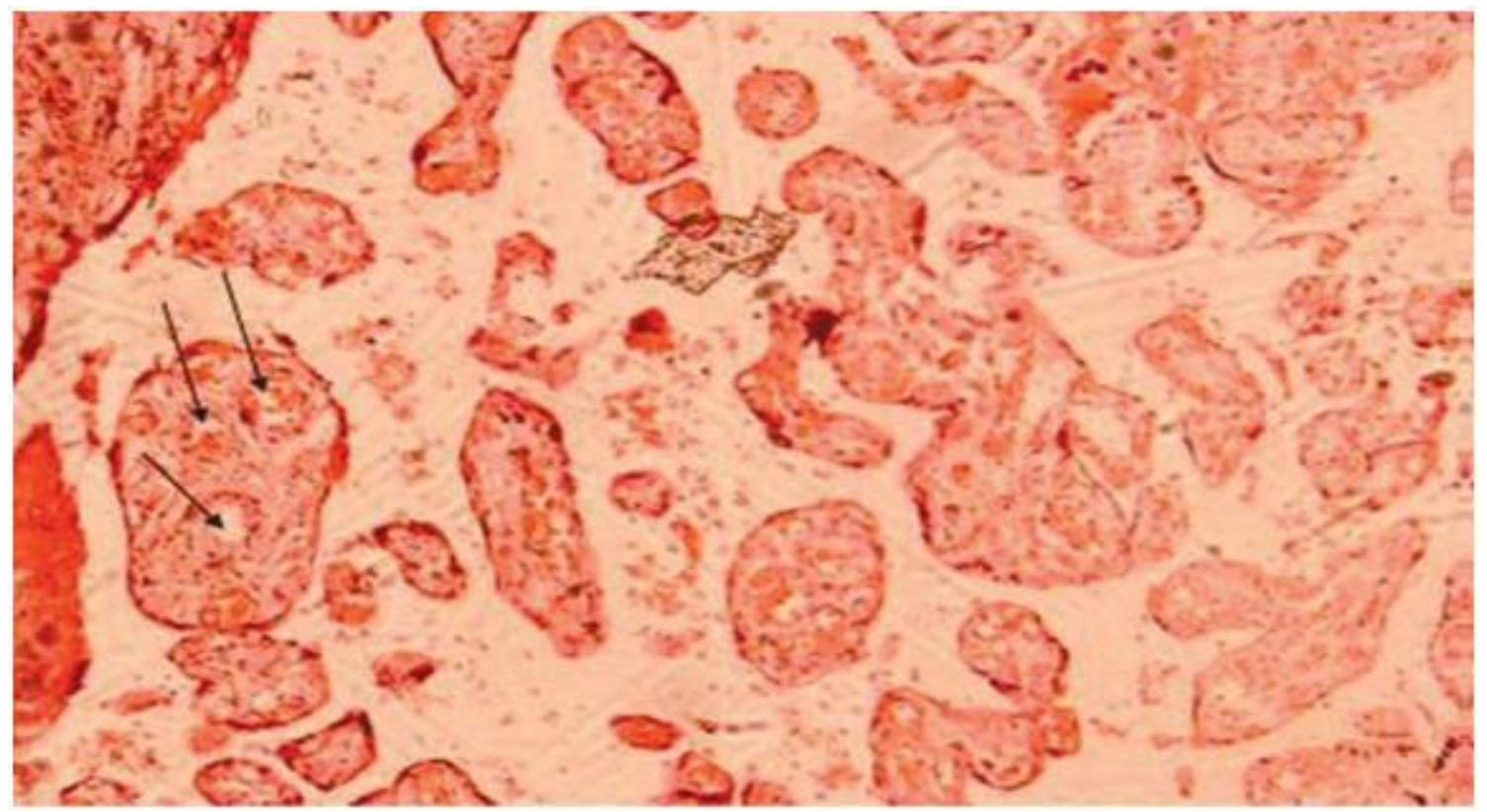

Arrow marked areas of capillary proliferation. (H \& E 40X)

Figure 5

Volume 4 Issue 12, December 2015

www.ijsr.net 


\section{International Journal of Science and Research (IJSR) \\ ISSN (Online): 2319-7064 \\ Index Copernicus Value (2013): 6.14 | Impact Factor (2014): 5.611}

\section{Discussion}

The placenta forms a functional unit between the mother and the fetus that plays pleiotropic role during fetal growth. Therefore, any pathological event that concerns the mother or the fetus will influence the normal function of the placenta, occasionally resulting in morphological and histological change. These abnormalities of the placenta may lead to adverse fetal outcome [12].Reports on the pathology of placenta in GDM are numerous but often contradictory. Theinconsistency may be explained in part, by the fact that thecategories of diabetic pregnant women are very heterogeneous [8].The delineation of placental lesions in maternal diabetes hasbeen also made unduly complex by the superimposedhypertension and other associated complications. In thepresent study, all the patients with GDM were perfectly controlled whatever the modality of treatment with insulin or without. Also other co-morbid condition such as hypertension, hypothyroidism, anaemia, jaundice, and maternal malnutrition even tobacco abuse, smoking, alcoholism etc. were excluded from study to create a chance of studying the true effect of GDM and modality of treatment on placenta without bias of other pathologic comorbid conditions or even diabetes control status which, of course well known active player.The weight of placenta is an important and functionally significant parameter as it is related to villous area and fetal metabolism. In the present study, the mean placental weight, the mean placental diameter, the mean placental central thickness and the mean placental surface area in GDM group controlled with insulin was more as compared to control group and this difference was found highly significant $(\mathrm{p}<0.01)$. Similar findings were reported inprevious studies by Verma et al (2010) [8], Chowdhury et al (2011) [13] and Saha et al (2014) [14]. The weight gain in placentae ofdiabetic mothers may be attributed tomacrosomia andcompensatory hyperplasia.Macrosomia affects the fetus and fetal part ofplacenta. Thismacrosmiamay be attributed to fetal hyperinsulenemia in response to hyperglycaemia infetuses of diabetic mothers $[1,3,15]$. The interesting point in the present study that, there are no significant differences of these parameters in GDM group controlled by diet without insulin and control group.Similar findings were reported inprevious study by Verma et al (2010) [8]. In the same track, several differences were identified in the lightmicroscopy of terminal villi from the placentae of GDM group controlled with insulin; large number of syncytial knots(Increased number of syncytiotrophoblastnuclei which showed chromatin clumping, a feature typical of senescence, and were usually arranged in clusters known as syncytialknots as defined by Jone\& Fox, 1977 [11]),fibrinoid necrosis, villous edema, villous fibrosis andproliferation of the capillaries. While placentas of GDMgroup controlled with diet alone without insulin showed minimally increased number of syncytialknots,fibrinoid necrosisand none of them showed villous edema,villous fibrosis or fetal capillary proliferationresemblingmore to the control group.More or less similar results were found in previous old studies $(16,17)$ where they found in addition fibrin necrosis and thickening of basal membrane of trophoblast in the placentaof poorly controlled diabetes.In our study, all the patients were perfectly controlled whatever the used modality with insulin or without. Of course, it would belogical to assume that the less severe and better controlledthe patients diabetic state, the less striking would be theplacental abnormalities but according to our results we add that, there is something in insulin itself apart from diabetes control had an impact in placental pathology in gestational diabetes. Actually, it is not big surprise as many of diabetes complications occur in controlled diabetic status and usually related to compensatory hyperinsulinemia of insulin resistance or induced by medications. Also we had no data aboutuncontrolled transitional period of shifting the patients from diet control to insulin yet in my opinion, it had no or minimal effect.Anyhow, large scale study include big number from different races are needed for more clarification.

\section{Conclusion}

The placentae ofwomenwith gestational diabetesmellitus treated with insulin even controlled showsignificant variation in gross morphology and light microscopy thatcan be associated with impaired function ofplacenta, leading to possible adverse perinataloutcome. In the other hand, the placentae ofwomenwith gestational diabetesmellitus controlled with diet alone showed minimal changes with no significant differences from normal uncomplicated pregnancy. Control of GDM or better prevention by education, diet, optimum weight control and life style modifications should be strictly encouraged and insulin use should be the last resort.

\section{References}

[1] Mukesh M. et al Gestational diabetes mellitus: An update on the current international diagnostic criteria. World J Diabetes 2015 June 25; 6(6): 782-791

[2] Kumar A, Goel MK, Jain RB, Khanna P, ChaudharyV.India towards diabetes control: Key issues.Australas Med J. 2013; 6(10):524-531.

[3] Pankaj S., Jai P., Anjali J.Gyan C. Effect of gestational diabetes mellitus on gross morphology of placenta: a comparative study.Int J Anat Res 2015; Vol 3(1):88994.

[4] Kalra P, Kachhwaha CP, Singh HV. Prevalence ofgestational diabetes mellitus and its outcome inwestern Rajasthan. Indian J EndocrMetab. 2013;17(4):677-680.

[5] Fox H, Neil J, editors. Pathology of the placenta. $3^{\text {rd }}$ ed. Philadelphia: Elsevier Saunders; 2007.

[6] Teasdale F. Gestational changes in the functionalstructure of the human placenta in class relationto fetal growth: amorphometric study. AmJObstetGynecol. 1980; 137: 560-8.

[7] Fox H. Pathology of the placenta in maternaldiabetesmellitus. Obstet Gynecol. 1969;34:792-8

[8] Verma R, MishraS,Kaul J. Cellular changes in the placenta in pregnancies complicated with diabetes. Int. J. Morphol.,28(1):259-264, 2010.

[9] Benirschke K. The placenta: How to examine it andwhat you can learn. ContempObst and Gynaecol.1981; 17:117-119. 


\section{International Journal of Science and Research (IJSR) \\ ISSN (Online): 2319-7064}

Index Copernicus Value (2013): 6.14 | Impact Factor (2014): 5.611

[10] Jones, C. J. \& Fox, H. Ultrastructure of the normal human placenta. Electron. Microsc. Rev., 4(1):129-78, 1991.

[11] Jones, C. J. \& Fox, H. Syncytial knots and intervillous bridges in the human placenta: an ultrastructural study. J. Anat., 124(Pt 2):275-86, 1977.

[12] HargitaiB, Marton T, Cox BM. Examination of humanplacenta. J clinPathol. 2004; 57:785-792.

[13] Chowdhury AHMMM, Shamim KM, Ferdousi R, BegumJA, Banu LA. A comparative study of effects of different grades ofmaternal established diabetes mellitus on placental and neonatal weight.Bangladesh $\mathrm{J}$ Anat. 2011; 9(1):53-58.

[14] Saha S, Biswas S, Mitra D, Adhikari A, SahaC.Histologic and morphometric study of human placenta in gestational diabetesmellitus. Ital J AnatEmbryol. 2014; 119(1):1-9.

[15] Queenan JT. Management of high risk pregnancy. 4th ed. England: Blackwell science; 1999; 261-70.

[16] Yang, H. X. Placental pathology in gestational diabetes. Zhonghua Fu Chan KeZaZhi, 28(12):714-6, 1993.

[17] al-Okail, M. S. \& al-Attas, O. S. Histological changes in placental syncytiotrophoblast of poorly controlled gestational diabetic patients. Endocr. J.; 41(4):355-60, 1994. 